\title{
EVALUATION OF SCATTERED RADIATION IN MAMMOGRAPHY EXAMINATION WITH Si DETECTOR
}

\author{
D. Adliené $\dot{a}^{\mathrm{a}}$ and I. Cibulskaitè $\dot{\mathrm{a}}^{\mathrm{a}, \mathrm{b}}$ \\ ${ }^{a}$ Kaunas University of Technology, Studentu 50, LT-51368 Kaunas, Lithuania \\ E-mail: diana.adliene@ktu.lt

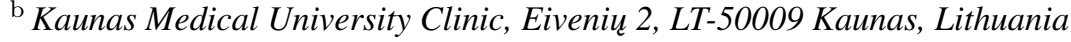 \\ E-mail: onko@takas.lt
}

Received 9 December 2005

\begin{abstract}
Monte Carlo simulations for interaction processes of low energy (23-25 keV) X-ray photons, which are commonly used in mammography examinations, are presented in this paper. The contribution of scattered radiation to the total dose is determined using scattering factor and the influence of scattered radiation for measurements with Si detector is investigated. Modelling results are compared with the results of experimental in vitro measurements using a phantom.
\end{abstract}

Keywords: scattered radiation, Compton scattering, glandular tissue dose, mammography, Monte Carlo method

PACS: $02.70 . \mathrm{Uu}, 29.40 . \mathrm{Wk}, 32.80 . \mathrm{Cy}$

\section{Introduction}

Certain amount of energy, which is characterized as absorbed dose, is transferred to the tissue during interaction processes of X-rays with biological structure. Absorbed dose is the main parameter defining radiation risk for the induced lethal cancer [1-3]. Keeping this dose as low as reasonably achievable $[4,5]$ or reducing it during medical examinations, is one of the most important problems in diagnostic radiology. It is impossible to measure absorbed dose in biological structure directly [6]. This dose can be recalculated using measured or simulated entrance surface dose (ESD) or entrance surface kerma (ESAK), X-ray spectrum parameters and applying different conversion factors, which are measured or simulated by Monte Carlo calculations. Due to this reason, ESD or ESAK are highly sensitive to the methods of the evaluation and depend strongly on the reliability of the results of calculations.

This work is focused on the investigation of interaction processes of low energy (23-35 keV) X-ray photons, which are used in mammography screening examinations. Mammography screening is preventative measure for detecting early stage cancer in the patient breast.

Usually ESAK and half value layer (HVL), which corresponds to the attenuation of X-rays entering interaction surface, are derived using ionization chamber.
Detector is placed at the characteristic point in exposure field without any presence of patient. ESAK values are calculated according to measured tube output, i. e. air kerma (mGy) relative to the tube loading (tube current and exposure time product, $\mathrm{mAs}$ ).

Solid state thermoluminescent detectors [7], optically stimulated luminescent detectors [8,9], and semiconductor devices [10] can be an alternative to ionization chambers for dose measurements. Measurement of ESD in vivo during mammography examinations when detector is positioned on the skin surface of the patient is complicated. It depends on the choice of registration method and measuring device, because every detector placed in between X-ray tube and examined organ or tissue is "visible" on X-ray image and can influence the evaluation of cancer cell clusters. Application of optical stimulated luminescence (OSL) dosimetry using $\mathrm{Al}_{2} \mathrm{O}_{3}: \mathrm{C}$ detector for in situ dose measurements reported in [8] seems to be very promising, but needs more detailed investigation.

Measurements of ESD in vitro are performed when detector is placed on the phantom surface. Measured ESD includes the contribution of backscatter radiation expressed in terms of backscatter factor (BSF):

$$
\mathrm{BSF}=\frac{\mathrm{ESD}}{\mathrm{ESAK}},
$$


which can be measured or calculated by means of Monte Carlo modelling technique.

Tabulated BSF values for the case of thermoluminescent dosimetry are presented in $[6,11,12]$. They have been approved and now are recommended for the use in mammography practice $[6,13]$. Despite of fact that semiconductor devices are used for in vitro phantom measurements [4], the contribution of backscattered radiation to the dose absorbed in semiconductor detectors is not investigated sufficiently.

The aim of this work is to simulate X-ray interaction processes with PMMA (polymethylmethacrylate) phantom in the presence of Si detector, to evaluate contribution of scattering dose to estimated ESD values, and to compare modelling results with the results of experimental in vitro measurements.

\section{Empirical models to describe scattering processes during low energy photon interactions with matter}

When low energy (23-35 keV) X-ray photons interact with matter, three interaction processes are dominant: photoelectric effect, coherent (Rayleigh) scattering, incoherent (Compton) scattering. We would like to discuss only scattering processes in this paper due to the important contribution of these processes to the ESD.

\subsection{Coherent (Rayleigh) scattering}

Coherent or Rayleigh scattering is the process by which photons are scattered without excitation of target atoms, i.e. the energies of the incident and scattered photons are the same. The scattering is qualified as "coherent" because it arises from the interference between secondary electromagnetic waves coming from different parts of the atomic charge distribution.

The atomic differential cross-section per unit solid angle $\Omega=(\theta, \phi)$ for coherent scattering is given approximately by [14]:

$$
\frac{\mathrm{d} \sigma_{\mathrm{R}}}{\mathrm{d} \Omega}=\frac{r_{0}^{2}}{2}\left(1+\cos ^{2} \theta\right)\left[F_{T}(q)\right]^{2},
$$

where $F_{T}(q)$ is the atomic form factor [15], given as

$$
\left[F_{T}(q)\right]^{2}=\sum_{i} p_{i}\left[F_{T}\left(q, Z_{i}\right)\right]^{2}
$$

with the stoichiometric index of the $i$ th element $p_{i}$, atomic number $Z_{i}$, and momentum transfer $q$ when a

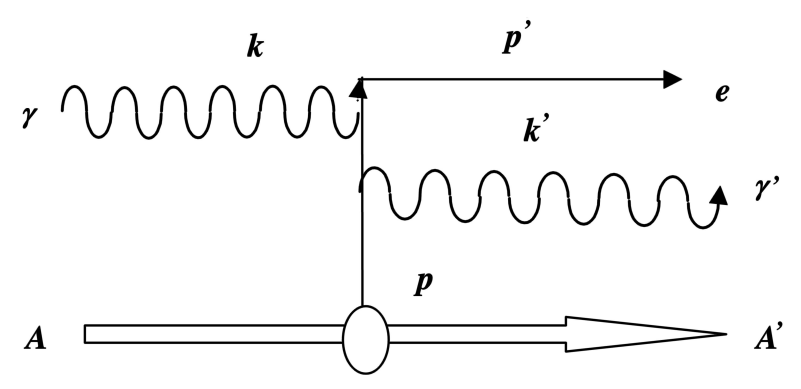

Fig. 1. Feynman diagram for the Compton process.

photon with the energy $k$ is scattered by polar scattering angle $\theta$ :

$$
q=k \sqrt{\frac{1-\cos \theta}{2}} .
$$

The quantity $r_{0}$ is the classical electron radius.

Equation (2) is adequate for photons with the energy well above the $\mathrm{K}$ absorption edge of target material. Nevertheless, at the higher energies where anomalous scattering effects become significant, coherent scattering is much less probable [16] than photoelectric absorption.

\subsection{Incoherent (Compton) scattering}

In Compton scattering, a photon with the energy $k$ interacts with an atomic electron, which absorbs it and re-emits secondary (Compton) photon of energy $k^{\prime}$ in the direction $\Omega=(\theta, \phi)$ relative to the direction of the original photon.

The Feynman diagram for the Compton process is presented in Fig. 1. The circle in the line of the incoming atom $\mathrm{A}$ indicates that the electron is initially bound to the atom and represents the probability that an atomic electron with a four-momentum $p=(E, \mathbf{p})$ interacts with the incoming photon with four-momentum $k=(k, \mathbf{k})$ into final $e^{-} \gamma^{\prime}$ state given by $k^{\prime}=\left(k^{\prime}, \mathbf{k}^{\prime}\right)$ and $p^{\prime}=\left(E^{\prime}, \mathbf{p}^{\prime}\right)$.

Following this scattering model, which includes binding effects and taking into account Doppler broadening, the incoherent scattering cross-section, differential in the photon scattering angle can be written as [17]

$$
\frac{\mathrm{d} \sigma_{\mathrm{Compt}}}{\mathrm{d} \Omega}=\frac{r_{0}^{2}}{2}\left(\frac{k_{c}}{k}\right)^{2} X_{\mathrm{KN}} S(k, \cos \theta),
$$

where $X_{\mathrm{KN}}$ is Klein-Nishina function [18] and $S(k, \cos \theta)$ can be identified as incoherent scattering function:

$$
S(k, \cos \theta)=\sum_{i} Z_{i} \Theta\left(k-U_{i}\right) S_{i},
$$


with $Z_{i}$ as an occupational number of the shell $i, U_{i}$ as a binding energy,

$$
S_{i}=\int_{-\infty}^{p_{i}} \mathrm{~d} p_{z} J_{i}\left(p_{z}\right) F\left(k, \cos \theta, p_{z}\right),
$$

and $J_{i}\left(p_{z}\right)$ as one-electron shell Compton profile.

Presented empirical models for the description of coherent and incoherent scattering events were used for modelling of photon interaction processes with matter and for the evaluation of the influence of scattering radiation to energy transport processes.

\section{Materials and methods}

\subsection{Simulation with EGSnrc code system}

Low energy X-ray photon interactions with matter were simulated using EGSnrc code system [19], modified according to the models described above. Individual photon histories were simulated and the history of each photon was followed until either all of its energy was transferred to electrons or it was absorbed locally. It was assumed that $10^{7}$ photons having energies increasing in $1 \mathrm{keV}$ increments from the range of $1-35 \mathrm{keV}$ in parallel beam, cross the mammography unit compression paddle and interact with a detec- tor, which is centrally placed on PMMA phantom of variable thickness. In Monte Carlo simulations phantom represented the female breast. Variations of phantom thickness introduced changes in the distance from the radiation source to the active detector surface. The space between focal spot of X-ray tube in mammography unit and imaging plate was divided into the areas. Division of the phantom area with the detector on its surface into zones according to the different densities and compositions of presented materials enabled to determine doses in each zone. Monte Carlo calculations were performed within cylindrical geometry (Fig. 2).

Polyenergetic X-ray photon spectra were processed using IPEM 1997 Spectrum Processor [20] for different X-ray tube potentials from the range of $23-32 \mathrm{kV}$, assuming the attenuation of the beam by $1 \mathrm{~mm}$ Be window of the tube, $0.03 \mathrm{~mm}$ Mo filter, and $3 \mathrm{~mm}$ thick polymethylmethacrilic compression paddle of mammography unit, when the tilting angle of Mo anode of the tube was $16^{\circ}$. Processed X-ray spectra were used as an input data in user code DOSnrc [21] for the calculation of total dose and dose caused by scattering events according to the model described above. It was assumed that the photon beam was parallel to $z$ axis in the central zone of interaction. Dose calculations were performed for Si and LiF detectors.

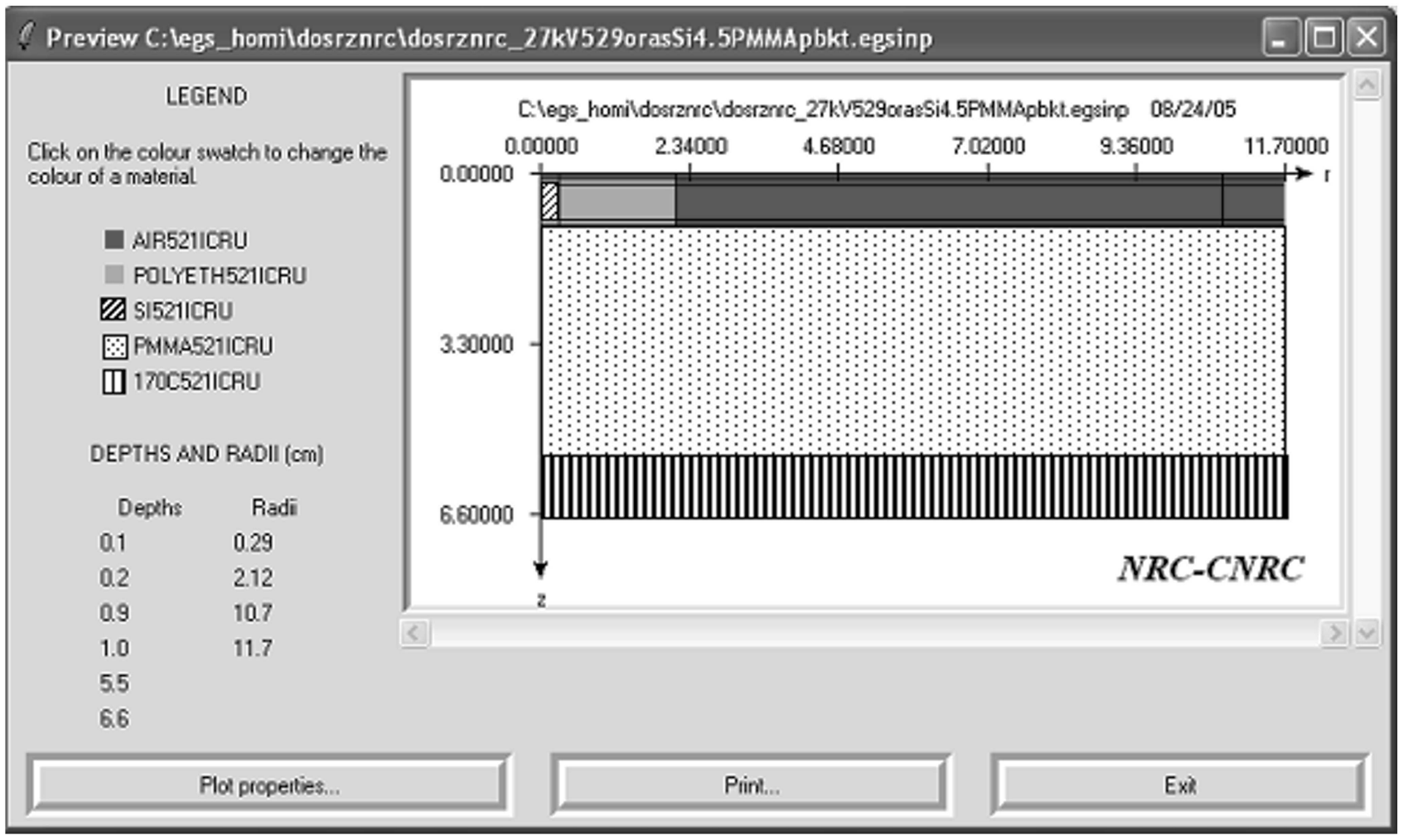

Fig. 2. RZ geometry in EGS code Monte Carlo calculations (not in scale). 


\subsection{In vitro dose measurements using silicon detector}

Experimental measurements were performed with "Instrumentarium Imaging" X-ray mammography unit "ALPHA RT" using Mo/Mo anode/filter combination. The tube potential ranged from 23 to $35 \mathrm{kV}$. A screen-film system "Kodak Min R2" was used for the imaging.

Entrance surface dose was measured using Si detector (UNFORS Mamo, calibrated 20050224 at UNFORS laboratory), which was placed laterally centred $60 \mathrm{~mm}$ from the chest wall side (as required in European Protocol on Dosimetry in Mammography [6]) on the top of the exposed PMMA phantom. PMMA phantom with a surface area of $240 \times 150 \mathrm{~mm}^{2}$ was combined to various thicknesses ranging from 20 to $80 \mathrm{~mm}$ and was used to simulate patient's breast thickness during mammography examinations. Experimental geometry is presented in Fig. 3.

Automatic exposure mode AEC of mammography unit was chosen to keep routine conditions in mammography screening, where the tube loading depended on compressed breast thickness, and the radiation output of the equipment varied linearly with the indicated tube loading for a given tube current and focal spot size [7]. Tube peak voltage, tube loading, and phantom thickness in each measurement were recorded together with detector readings of entrance surface dose and dose rate. Energy corrections for measured doses were performed according to the recommendations provided by Si detector manufacturers.

\section{Results and discussions}

Molybdenum is commonly used as a target material in X-ray mammography units in order to achieve the required radiographic contrast in the soft tissue of the female breast. X-ray spectra are dominated by molybdenum $\mathrm{K}$ line energies of $17.38 \mathrm{keV}\left(\mathrm{K}_{\alpha 2}\right), 17.49 \mathrm{keV}$ $\left(\mathrm{K}_{\alpha 1}\right), 19.61 \mathrm{keV}\left(\mathrm{K}_{\beta 1}\right)$, and $19.96 \mathrm{keV}\left(\mathrm{K}_{\beta 2}\right)$ [20]. The use of molybdenum filters (Mo/Mo combination) enhances the effects attenuating photons with the energies below about $10 \mathrm{keV}$ and above $20 \mathrm{keV}$.

Polyenergetic X-ray molybdenum spectra attenuated by $1 \mathrm{~mm}$ beryllium, $0.03 \mathrm{~mm}$ molybdenum filter, and $3 \mathrm{~mm}$ polymethylmethacrylate compression plate are processed for different tube potentials in the case of the constant source detector distance, corresponding to the "standard" PMMA phantom thickness $(45 \mathrm{~mm})$ as it is shown in Fig. 4.

Variations in the shape of processed spectra are caused by interaction processes, when X-ray photons of different energy enter attenuating materials. Inclusion of the photon attenuation by compression paddle makes it possible to smooth the differences in dose simulations, caused by photon scattering from areas other than the phantom or detector area. The first half value layer (HVL) in mm of Al calculated for attenuated photon beam at the different tube potentials is presented in the Table 1.

The results of present calculations are very similar to those referred by Jansen, Dierker, and Zoetelief [22] and differ only within $2.5-5.2 \%$.

Table 1. Values of the first HVL as a function of X-ray tube potential.

\begin{tabular}{|c|c|c|c|c|c|c|c|c|}
\hline Tube potential, kV & 25 & 26 & 27 & 28 & 29 & 30 & 31 & 32 \\
\hline HVL, Al mm (present work) & 0.3224 & 0.3338 & 0.3441 & 0.3537 & 0.3625 & 0.3708 & 0.3786 & 0.3859 \\
\hline HVL, Al mm ([22]) & 0.34 & - & - & 0.37 & - & 0.38 & 0.39 & - \\
\hline \multirow{3}{*}{\multicolumn{2}{|c|}{ Compression paddle }} & & & & & \multirow{2}{*}{\multicolumn{2}{|c|}{$\begin{array}{l}\text { Source- } \\
\text { detector } \\
\text { distance }\end{array}$}} & \\
\hline & & & & & Air gap & & & \\
\hline & & & & & & & & \\
\hline \multicolumn{2}{|c|}{ Detector } & & & & \multicolumn{3}{|c|}{$\begin{array}{l}\text { PMMA phantom of } \\
\text { variable thickness }\end{array}$} & \\
\hline
\end{tabular}

Fig. 3. Experimental geometry. 


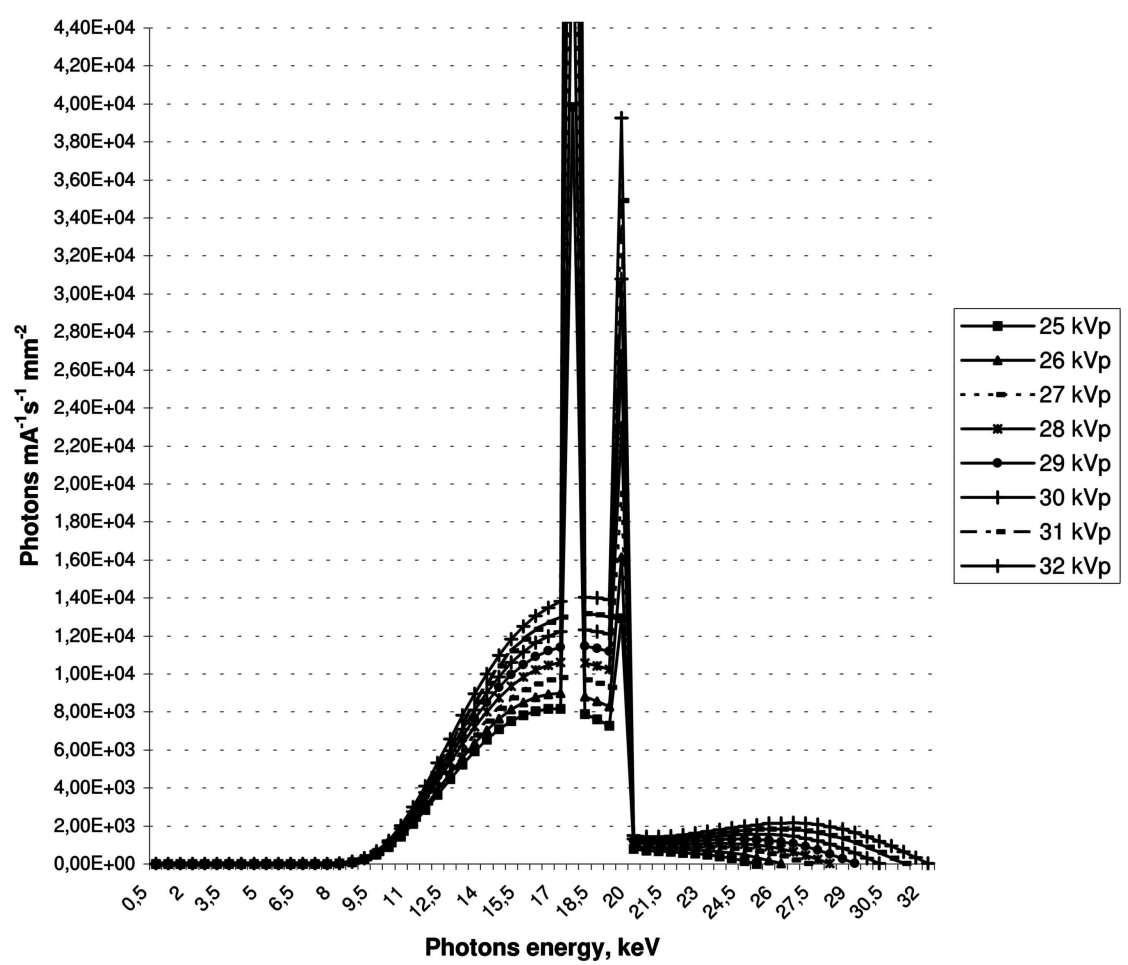

Fig. 4. Molybdenum X-ray spectra for different tube potentials. Photons are attenuated by $1 \mathrm{~mm} \mathrm{Be}, 0.03 \mathrm{~mm}$ Mo, $529.97 \mathrm{~mm}$ air (45 mm PMMA), 3 mm compression paddle.

Some of the X-ray photons from generated low energy spectra are scattered when they interact with a target material. According to the results published by different authors $[23,24]$ the scattered radiation in mammography contributes to the total registered radiation with $40-80 \%$. Backscattering directions of approximately $180^{\circ}$ and $90^{\circ}$ dominate for low energy photons. Two parallel scattering processes contribute to the total absorbed dose in detector: backscattering from the phantom surface and scattering in detector material. Monte Carlo simulated total doses, calculated in accordance with the model described above, for Si detector are presented in Fig. 5, and the scattering doses related to Compton scattered photons are given in Fig. 6.
The influence of phantom thickness on the scattered fraction of photons is not significant in the case of "thick" Si detector. Scattered fraction of Compton photons increases nearly uniformly with the increase of tube voltage, which is directly related to the energy of photons, and contributes to the increased total dose. Scattering dose reflects the contribution of photons scattered in detector material without significant contribution of photons scattered from PMMA phantom.

Some differences can be outlined when analysing the Monte Carlo calculated doses for $\mathrm{LiF}$ detector as it is shown in Figs. 7 and 8.

The values of Monte Carlo calculated doses for

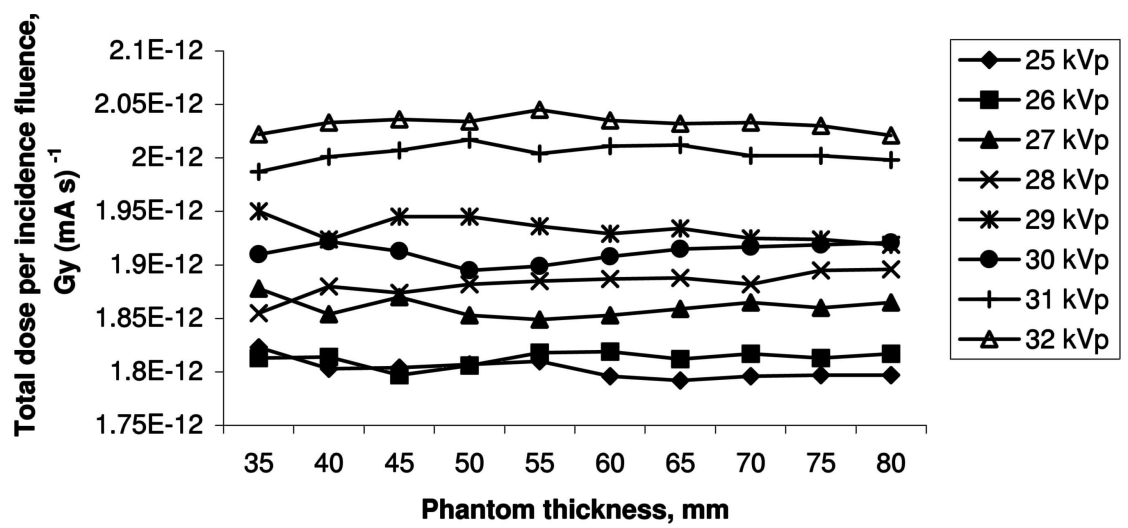

Fig. 5. Variations of total doses with the phantom thickness as calculated for Si detector. 


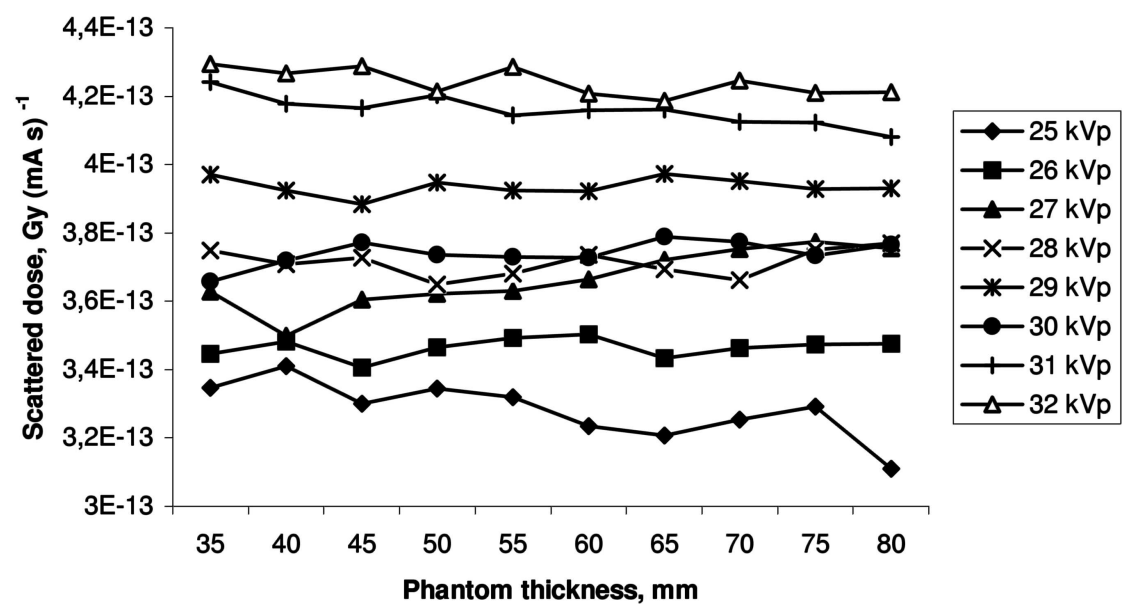

Fig. 6. Scattering doses at different phantom thicknesses as calculated for Si detector.

different phantom thicknesses are spread within the interval between the maximum and minimum doses for the range of applied tube potentials. Dose variations depend on the electronic structure of $\mathrm{LiF}$ and the sensitivity of photon registration mechanism. On the other hand the small size of $\mathrm{LiF}$ detector $3.2 \times 3.2 \times 0.9 \mathrm{~mm}^{3}$ as compared to volume $\mathrm{Si}$ detector corresponds to the increased number of photons backscattered from PMMA phantom that enter the detector surface.

The contribution of scattered radiation to the total doses is expressed as a scattering factor (SF):

$$
\mathrm{SF}=\frac{\mathrm{TD}}{\mathrm{TD}-\mathrm{SD}},
$$

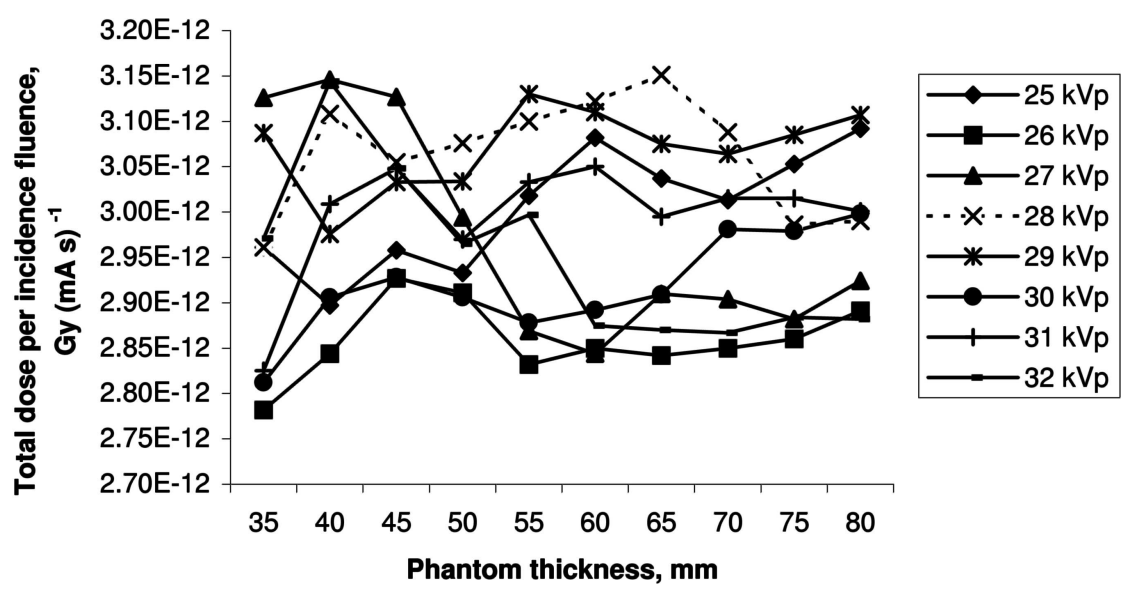

Fig. 7. Variations of total dose with the phantom thickness as calculated for LiF detector.

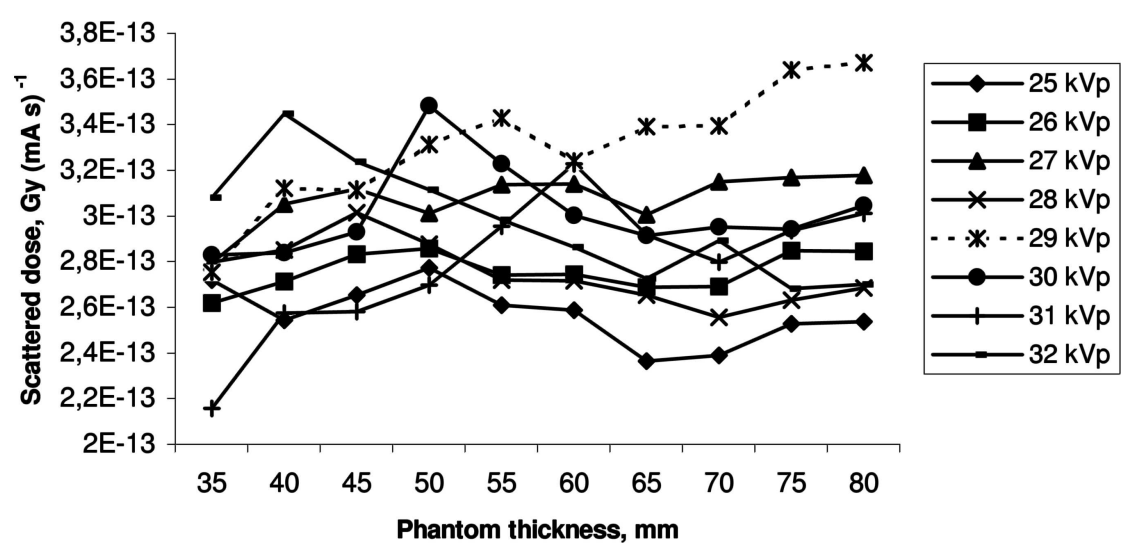

Fig. 8. Scattering doses at different phantom thicknesses as calculated for LiF detector. 


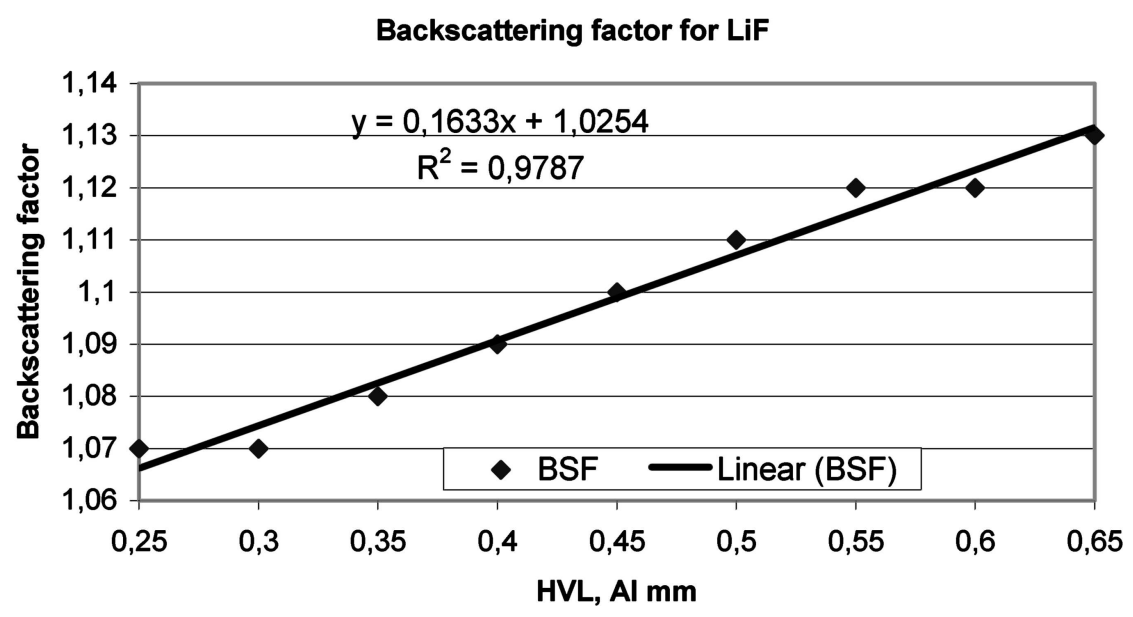

Fig. 9. Dependence of backscattering radiation on X-ray beam attenuation.

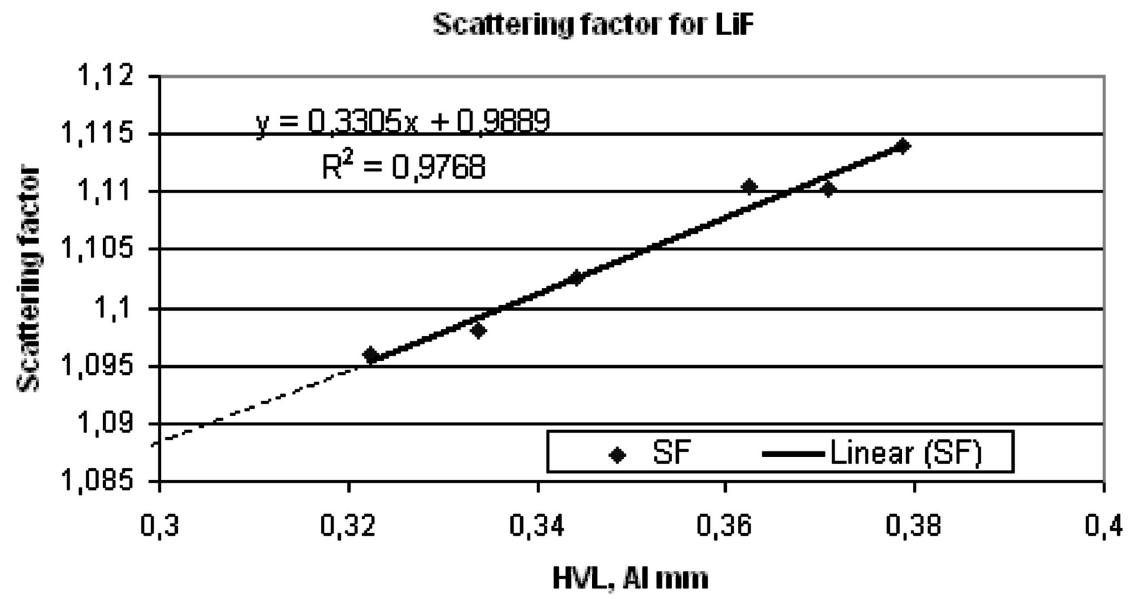

Fig. 10. Dependence of calculated scattering factor on X-ray beam attenuation.

Table 2. Scattering factor for $\mathrm{Si}$ and $\mathrm{LiF}$ detector.

\begin{tabular}{ccccccccc}
\hline HVL, Al mm & 0.322 & 0.334 & 0.344 & 0.354 & 0.363 & 0.371 & 0.379 & 0.386 \\
Scattering factor for Si & 1.223 & 1.236 & 1.245 & 1.246 & 1.253 & 1.259 & 1.268 & 1.272 \\
Scattering factor for LiF & 1.094 & 1.099 & 1.103 & - & 1.111 & 1.115 & 1.114 & 1.112 \\
\hline
\end{tabular}

Scattering factors derived from Monte Carlo calculations for different X-ray beam attenuations are given in Table 2 for $\mathrm{Si}$ and LiF detectors respectively. Evaluated scattering factor for $\mathrm{LiF}$ is comparable with the data for backscattering factor stated by other authors [22, 25], as it is shown in Figs. 9 and 10.

Scattering factor values approximated from our Monte Carlo calculations are slightly higher and differ within $10 \%$ from the values used for calculations of the in-breast absorbed doses in mammography [6]. The differences can be explained taking into account that BSF is calculated for the ESD and SF is recalculated from total dose, absorbed in $\mathrm{LiF}$, which includes not only scattered photon fraction from the PMMA surface but additionally small fraction of Compton scattered photons in the detector material.
Photons scattered in the detector volume contribute significantly to the total absorbed dose in the case of the "thick" and less dense Si detector $\left(\rho(\mathrm{Si})=2.33 \mathrm{~g} / \mathrm{m}^{3}\right.$, $\left.\rho(\mathrm{LiF})=2.64 \mathrm{~g} / \mathrm{m}^{3}\right)$, as it can be assumed from the Table 2. The dose absorbed in air at the detector surface will be different as compared to the dose absorbed in the volume. Calculations show that division of total absorbed dose by scattering factor in the case of thick Si detector gives the values (Fig. 11), which are in good agreement with the absorbed doses in air measured with the same detector. ESD measurements were performed during irradiation of phantoms of different thicknesses at mammography unit when AEC system was used (Fig. 12).

The results discussed above show that it is possible to use $\mathrm{Si}$ detector instead of $\mathrm{LiF}$ for the ESD 


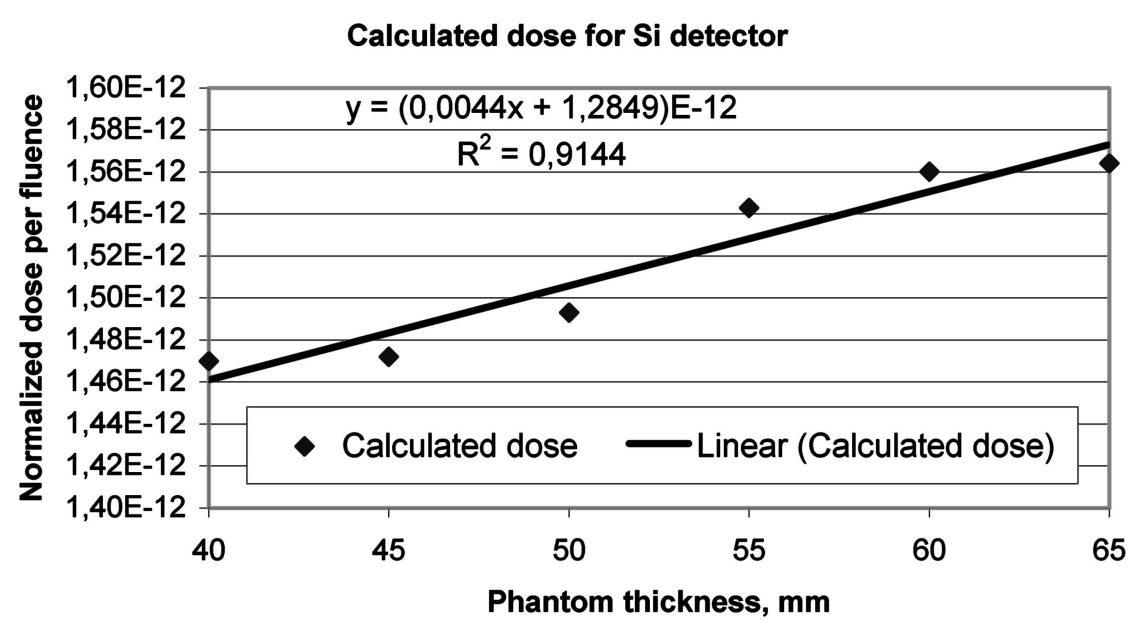

Fig. 11. ESD for Si derived from Monte Carlo calculated dose.

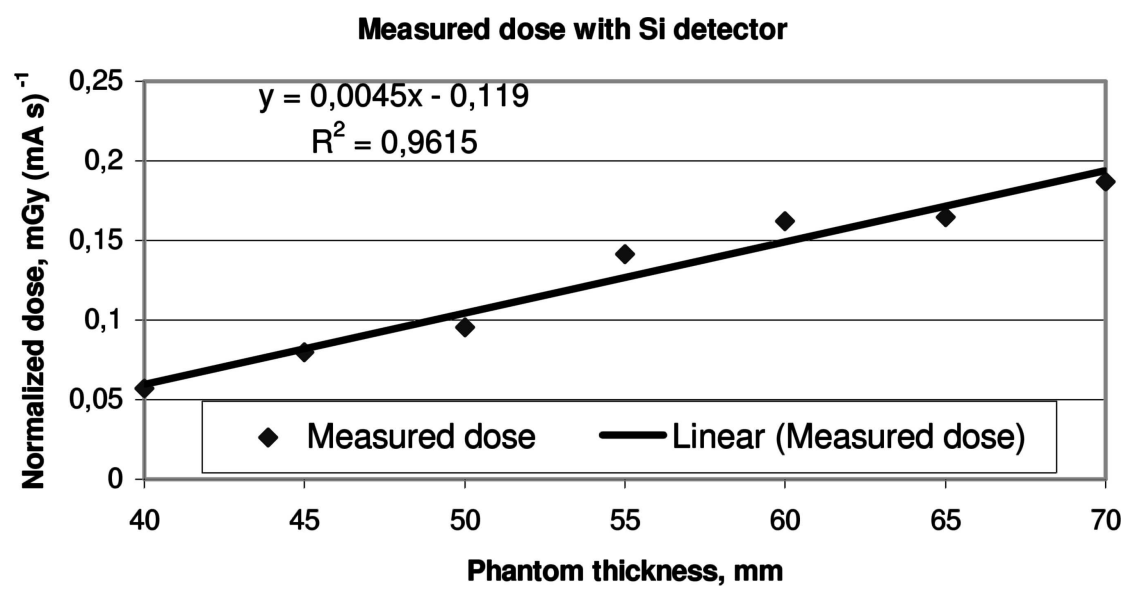

Fig. 12. ESD for Si measured during mammography examinations.

measurements on phantom surface when the scattering effects in detector volume are taken into account.

\section{Conclusions}

Using modified model of photon interaction processes with matter, presented in this paper, Monte Carlo dose calculations are being performed with the purpose to evaluate the influence of scattered fraction to the total dose absorbed in the phantom of variable thickness. It is shown that the contribution of scattered radiation expressed in terms of scattering factor derived from Monte Carlo calculations is comparable to the results stated by other authors for $\mathrm{LiF}$ detector. The differences in backscattering factor values within $10 \%$ comply with the recommendations of European Protocol on Dosimetry in Mammography [6] for the uncertainty limits.

When $\mathrm{Si}$ detector is used instead of $\mathrm{LiF}$ for the dose measurement on the phantom surface, scattering effects in detector volume should be taken into account. Af- ter correction of calculated dose by scattering factor in detector material, measured and calculated doses show the same increasing tendency with increasing phantom thickness.

It is suggested that the correction of the calculated dose values by scattering factor, which is evaluated using the same simulation model as in the case of $\mathrm{LiF}$, makes it possible to use Si detector for phantom measurements and for the further estimation of patient doses absorbed in glandular tissue of the breast during mammography examinations.

\section{Acknowledgement}

Present work is supported by the Lithuanian State Science and Studies Foundation.

\section{References}

[1] I. Andersson and I. Janzon, Reduced breast cancer mortality in women under age 50: Updated re- 
sults from Malmo Mammographic Screening Program, J. Natl. Cancer Inst. Monogr. (22), 63-67 (1997).

[2] M. Ramos, S. Ferrer, J.I. Villaescusa, G. Verdu, M.D. Salas, and M.D. Cuevas, Use of risk projection models to estimate mortality and incidence from radiation induced breast cancer in screening programs, Phys. Med. Biol. 50, 505-520 (2005).

[3] J. Law and K. Faulkner, Cancers detected and induced, and associated risk and benefit, in breast screening programme, Br. J. Radiol. 74, 1121-1127 (2001).

[4] N. Perry, M. Broeders, C. de Wolf, and S. Tornberg, European Guidelines for Quality Assurance in Mammography Screening (EUREF, European Commission, 2001).

[5] EURATOM. The European medical exposure directive 97 / 43 Euratom on health protection of individuals against the dangers of ionizing radiation in relation to medical exposure, Official J. European Communities (L 180), 22-27 (1997).

[6] J. Zoetelief, M. Fitzgerald, W. Leitz, and M. Sabel, European Protocol on Dosimetry in Mammography EUR 16263 (European Commission, Luxemburg, 1996).

[7] J. Zoetelief, A.H.L. Aalbers, L.B. Beentjes, J.J. Broerse, H.W. Julius, and C. Zuur, Dosimetric Aspects of Mammography, Report 6 of the Netherlands Commission on Radiation Dosimetry (1993).

[8] M.C. Aznar, B. Hemdal, J. Medin, C.J. Markman, C.E. Andersen, L. Bøtter-Jensen, I. Andersson, and S. Mattsson, In vivo absorbed dose measurements in mammography using a new real time luminescence technique, Br. J. Radiol. 78, 328-334 (2005).

[9] L. Bøtter-Jensen and S. McKeewer, Optically stimulated luminescence dosimetry using natural and synthetic materials, Radiat. Prot. Dosimetry 65, 273-280 (1996).

[10] C.A. Carlsson and G.A. Carlsson, Dosimetry in diagnostic radiology and computerized tomography, in: The Dosimetry of Ionizing Radiation, Vol. III, ed. F.H. Attix (Academic Press, New York, 1990) pp. 163220.

[11] D. Dance, Monte Carlo calculations of conversion factors for the estimation of mean glandular breast dose, Phys. Med. Biol. 35, 1211-1219 (1990).

[12] D. Dance, C. Skiner, K. Young, J. Beckert, and C. Kotre, Additional factors for the estimation of mean glandular breast dose using UK mammography dosimetry protocol, Phys. Med. Biol. 45, 3225-3240 (2000).
[13] R. Van Egen, K. Young, H. Bosmans, and M. Thijssen, Addendum of Digital Mammography. Guidelines for Quality Assurance in Mammography Screening (EUREF, European Commission, Nijmegen, The Netherlands, 2003).

[14] M. Born, Atomic Physics (Blackie and Son, London, 1969).

[15] J.H. Hubel and I. Overbro, Relativistic atomic form factors and photon coherent scattering cross section, J. Phys. Chem. Ref. Data 9, 69 (1979).

[16] E. Storm and H.I. Israel, Photon cross sections from $1 \mathrm{keV}$ to $100 \mathrm{MeV}$ for elements $Z=1$ to $Z=100$, At. Data Nucl. Data Tables 7, 565-681 (1970).

[17] R. Ribberfors, Relationship of the Compton cross section to the momentum distribution of bound electron states, Phys. Rev. B 12, 2067-2074 (1975).

[18] O. Klein and Y. Nishina, Über die Streuung von Strahlung durch freie Elektronen nach der neuen relativistischen Quantendynamik von Dirac, Z. Physik 52, 853-868 (1929).

[19] I. Kawrakow and D.W.O. Rogers, The EGSnrc Code System. Monte Carlo Simulation of Electron and Photon Transport (National Reasearch Council of Canada, 2003). http: / / www.irs.inms.nrc.ca.

[20] K. Cranley, B.J. Gilmore, G.W.A. Fogarty, and I. Desponds, Catalogue of Diagnostic X-ray Spectra and Other Data, Institute of Physics and Engineering in Medicine, Report No. 78 (1997).

[21] D.W.O. Rogers, I. Kawrakow, J.P. Seuntjens, B.R.B. Walters, and E. Mainegra-Hing, NRC User Codes for EGSnrc (National Reasearch Council of Canada, 2003).

[22] J.T.M. Jansen, J. Dierker, and J. Zoetlief, Calculations of air kerma to mean glandular dose conversion factors for mammography units employing various target-filter combinations, in: Proceedings of the Xth Scientific Symposium of the Belgian Society of Hospital Physicists (Belgian Society of Hospital Physicists, Antwerpen, 1994), pp. 66-75.

[23] N. Meriç, D. Bor, and N. Büget, Determination of scatter fractions of some materials by experimental studies and Monte Carlo calculations, Appl. Radiat. Isotopes 51, 161-167 (1999).

[24] J.M. Boon, K.K. Lindfors, V.N. Cooper III, and J.A. Seibert, Scatter / primary in mammography: Comprehensive result, Med. Phys. 27, 1300-1310 (2000).

[25] K. Shimizu, K. Koshida, and T. Miaty, Monte Carlo simulation analysis of backscatter factor for low energy X-ray, in: Proceedings of the 9th EGS4 users meeting in Japan, KEK Proceedings 2001-22, 115-118 (2001). 


\title{
IŠSKLAIDYTOSIOS SPINDULIUOTĖS INDE்LIO VERTINIMAS MAMOGRAFINIAME TYRIME PANAUDOJANT Si DETEKTORIU
}

\author{
D. Adlienè ${ }^{\mathrm{a}}$, I. Cibulskaitè ${ }^{\mathrm{a}, \mathrm{b}}$

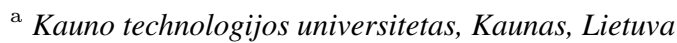 \\ ${ }^{\mathrm{b}}$ Kauno medicinos universiteto klinikos, Kaunas, Lietuva
}

\section{Santrauka}

Pristatomi mažų energijos verčių (23-25 keV) Rentgeno fotonų, kokie naudojami mamografinių tyrimų metu, sąveikos su PMMA (polimetilmetakrilato) fantomu Monte Karlo modeliavimo rezultatai. Nustačius sklaidos koeficientus, vertinama sklaidos dèl
Relejjaus (Rayleigh) ir Komptono (Compton) sąveikos ittaka apskaičiuotajai dozei. Monte Karlo modeliavimo rezultatai palyginami su eksperimentiniais duomenimis, gautais matuojant in vitro. Remiantis rezultatu analize, svarstoma galimybė naudoti Si detektorius dozèms medicininiame fantome ivvertinti. 